\title{
EFFECTS OF FELINE PANLEUCOPAENIA ON THE POPULATION CHARACTERISTICS OF FERAL CATS ON MARION ISLAND
}

\author{
BY P. J. J. VAN RENSBURG*, J. D. SKINNER $\dagger$ AND R. J. VAN AARDE
}

\author{
Mammal Research Institute, University of Pretoria, Pretoria 0002, South Africa
}

\begin{abstract}
SUMMARY
(1) This paper evaluates the effects of the artificial introduction of feline panleucopaenia (FPL) as a primary control measure of a feral cat population on the sub-Antarctic Marion Island $\left(46^{\circ} 54^{\prime} \mathrm{S}, 37^{\circ} 45^{\prime} \mathrm{E}\right)$.

(2) The population decreased from an estimated 3409 cats in 1977 (introduction of control factor) to 615 (S.E. $=107$ ) cats during 1982, suggesting an annual rate of decrease of $29 \%$.

(3) Litter size decreased and the age structure changed significantiy because of a decrease in subadult numbers. Age specific mortality rates were higher but followed the same pattern as in 1975 because there were fewer subadults but the same age structure of adults.

(4) The intrinsic rate of increase, as suggested by the survival and fecundity schedules of the population, was higher in 1975 owing to a greater proportion of adults and a higher fecundity in age class II.

(5) Antibody titres of FPL were lower in 1982 than in 1978 which illustrates that FPL did affect the cat population but is no longer spreading effectively. FPL was independent of feline herpes (FVR), an endemic disease of the cat population, and FPL was, therefore, directly responsible for the decrease in cat population density.

(6) During 1982 the cat population showed a decrease of $8 \%$ year $^{-1}$, which indicates stabilizing of the negative growth rate. This observation was supported by lower titres of FPL.
\end{abstract}

\section{INTRODUCTION}

The accidental and/or deliberate introduction of exotic predators to islands has severely affected indigenous bird populations. The estimated 2139 (S.E. $=290)$ descendants of a founder group of five feral cats (Felis catus Linn.), introduced to Marion Island in 1949, were killing some 450000 petrels (Family Procellariidae) each year by 1975 . The predicted annual increase of the number of birds killed was equalled by the observed population increase of cats of c. $23 \%$ year $^{-1}$ (van Aarde 1978, 1980). In order to control the susceptible and isolated population of cats, feline parvo virus was introduced during 1977 in an attempt to create an epidemic of the disease feline panleucopaenia (FPL).

The properties and epideniology of FPL in relation to the Marion cat population have been outlined by Howell (1984). FPL is a highly contagious, host-specific disease, mainly of domestic cats, where morbidity in a susceptible population often approaches $100 \%$. High mortality rates are most prevalent amongst kittens. The virus is excreted in high concentrations in faeces, urine, saliva and vomit, is resistant to many chemicals and has a wide temperature tolerance. Transmission usually occurs through direct contact between susceptible and infected cats but can also occur indirectly through contact with contaminated objects (Fastier 1968; Gillespie \& Scott 1973).

\footnotetext{
* Present address: Division of Nature Conservation, Private Bag X209, Pretoria 0001, South Africa

$\uparrow$ To whom correspondence should be addressed.
} 
Marion Island $\left(46^{\circ} 54^{\prime} \mathrm{S}, 37^{\circ} 45^{\prime} \mathrm{E}\right)$ is a sub-Antarctic island of approximately $290 \mathrm{~km}^{2}$ in the Southern Indian Ocean. It is of volcanic origin with a tundra biota experiencing low temperatures and strong winds (Huntley 1967; Verwoerd 1971; Schulze 1971).

In the present paper we evaluate the hypothesis that FPL is an effective control measure by comparing the population characteristics of cats in 1975, before introduction of FPL, with those in 1982 following introduction of the virus in an attempt at biological control of the cats to conserve the avifauna.

\section{MATERIALS AND METHODS}

Characteristics for the 1982 population were derived from material and information obtained between April 1981 and May 1983, these being collected and analysed as described for the 1975 population (van Aarde 1978, 1979, 1983; van Aarde \& Robinson 1980). The data collected by van Aarde during 1975 were used as a control.

Density and population estimates were extrapolated from data collected in a study area of $32.8 \mathrm{~km}^{2}$, which was stratified into a coastal $(0-100 \mathrm{~m}$ a.s.l.) and an interior zone (100$450 \mathrm{~m}$ a.s.l.), and divided into equal sized $\left(0.67 \mathrm{~km}^{2}\right)$ grid blocks (van Aarde 1979). The area was surveyed on foot at monthly intervals and individual identification was based on coat colour patterns and body size. Resightings were excluded from the data and population size $(\hat{Y})$ was estimated as

$$
\hat{Y}=\sum_{i} N_{\mathrm{i}} \bar{y}_{\mathrm{i}}
$$

where $N_{i}$ is the total number of grid blocks in the $i$ th zone and $\bar{y}_{i}$ is the average number of cats in each of the sampled grid blocks. The standard error of $\hat{Y}$ was obtained using

$$
\operatorname{var} \hat{Y}=\sum_{i} \frac{N_{i}\left(N_{i}-n_{i}\right)}{n_{i}} S_{y_{i}}^{2}
$$

where

$$
S_{y_{i}}^{2}=\frac{1}{\left(n_{i}-1\right)} \sum_{i}\left(y_{i j}-\bar{y}_{i}\right)^{2}
$$

$y_{i j}$ is the number of cats in the $j$ th observed grid block of the $i$ th zone and $n_{i}$ is the number of sampled grid blocks (Jolly 1969). Estimates of population growth rate $(r)$ are based on the exponential function $N_{t}=N_{0} e^{\mathrm{rl}}$ where $N_{t}$ is the population size at time $t, N_{o}$ is the population size at time zero and $e$ is the base of natural logarithms (Caughley 1977).

All cats were grouped into age classes, according to body size, as adult, subadult and juvenile (van Aarde 1978). Coat colour phenotypes were scored as described by van Aarde \& Robinson (1980). Reproductive status was recorded and the skull and serum were collected from cats culled between January and May 1982 and between October 1982 and May 1983. Age determination of cats with a permanent dentition was based on counts of cementum lines in teeth (van Aarde 1983). Population parameters were estimated as discussed in van Aarde (1983). The Leslie type of fecundity $\left(F_{x}\right)$ was used where $F_{x}=m_{x} \cdot l_{1}, F_{x}$ is the number of female offspring produced per female in each age class that will survive to enter the first age class, $m_{x}$ is the age specific fecundity and $l_{1}$ is the 


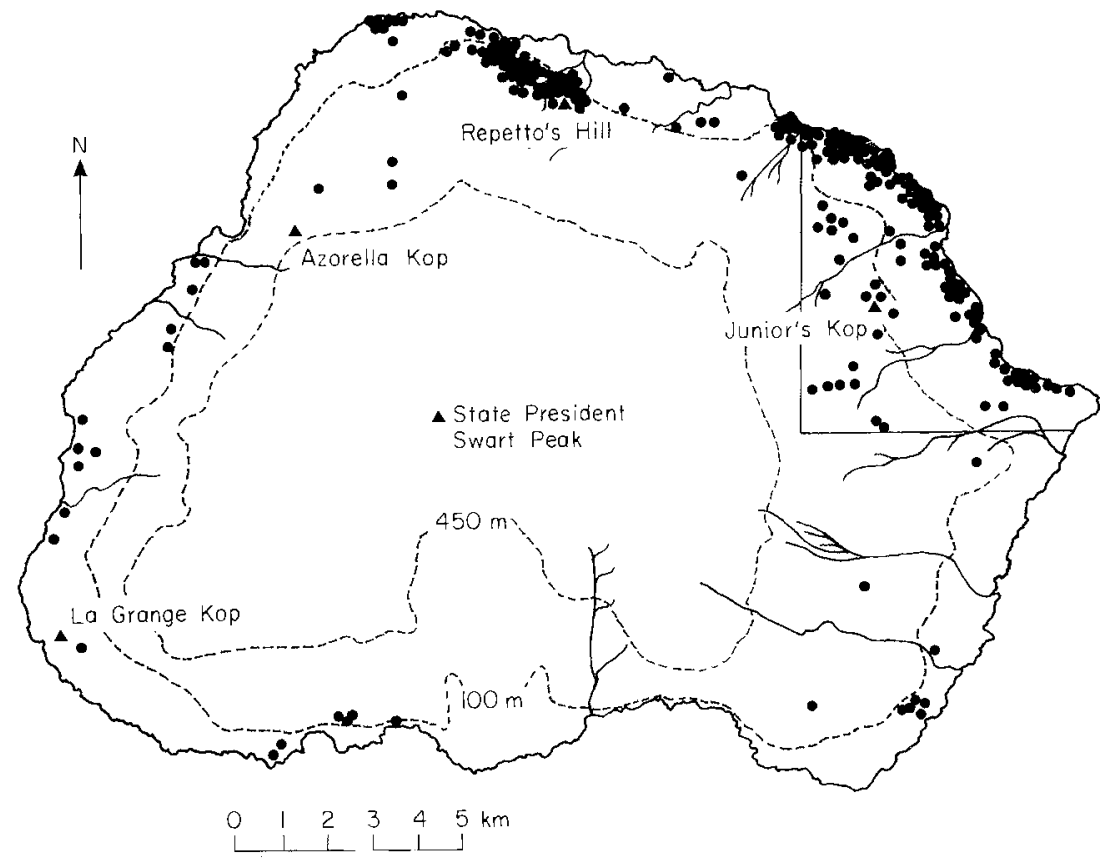

FIG. 1. Distribution of feral cats on Marion Island (46 $\left.54^{\prime} \mathrm{S}, 37^{\prime} 45^{\prime} \mathrm{E}\right)$ in 1982 based on 258 sightings.

probability that newborn will survive to enter the first age class (Michod \& Anderson 1980), $l_{1}$ being estimated as

$$
\frac{\text { prenatal litter size }}{\text { post-weaning litter size }} \text {, }
$$

based on the assumption that the litter size at birth $=$ prenatal litter size. The intrinsic rate of -increase $(r)$ was calculated from:

$$
\lambda=\sum_{x=1}^{n} \frac{N_{\mathrm{x}} F_{\mathrm{x}}}{N_{1}},
$$

where $N_{x}$ is the number of animals in age class $x, N_{1}$ is the number of animals in age class 1 and $F_{x}$ is Leslie's age specific fecundity and where $r=\ln \lambda($ Michod $\&$ Anderson 1980). The statistics $l_{x}, s_{x}, p_{x}$ and $q_{x}$ were estimated according to Caughley (1977). Age frequencies were corrected by assigning cats collected during the 1982-83 season to the 1981-82 season (observed age -1 ). Correction of age frequencies is based on the assumption of an equal sampling intensity during the study period. Age frequencies were smoothed using a log-polynomial function following Caughley (1977).

Serum samples were analysed for antibodies of FPL with the haemagglutination inhibition test and for antibodies of feline herpes (feline viral thinotracheitus, FVR) with the serum neutralization test (Johnson 1971). 
TABLE 1. The Marion Island cat population size estimated from densities derived from the selected study area ( $N_{\mathrm{i}}$ is the total number of grid blocks, $n_{\mathrm{i}}$ is the number of grid blocks surveyed, $y_{\mathrm{i}}$ is the average number of cats per grid block, $\hat{Y}$ is the population size and var $\hat{Y}=$ variance)

\begin{tabular}{|c|c|c|c|c|c|}
\hline Zone & $\left(N_{i}\right)$ & $\left(n_{\mathrm{i}}\right)$ & $\left(y_{i}\right)$ & $(\hat{Y})$ & $(\operatorname{var} \hat{Y})$ \\
\hline Coastal & 148 & 29 & 3.00 & 444.00 & $8545 \cdot 72$ \\
\hline Interior & 202 & 20 & 0.85 & $171 \cdot 70$ & 2955.63 \\
\hline \multirow[t]{2}{*}{ Total } & 350 & 49 & & $615 \cdot 70$ & 11501.35 \\
\hline & & & & & $\sqrt{ } 11501 \cdot 35=107$ \\
\hline
\end{tabular}

TABLE 2. Age structure of the 1975 (control) and 1982 cat populations of Marion Island based on field observations of cats

\begin{tabular}{lccccr} 
& \multicolumn{2}{c}{1975} & \multicolumn{2}{c}{1982} & $\chi^{2}$ \\
& Number & Percentage & Number & Percentage \\
Juvenile & 76 & $11 \cdot 4$ & 20 & $9 \cdot 8$ & 0.24 \\
Subadults & 163 & $24 \cdot 5$ & 15 & $7 \cdot 4$ & $22 \cdot 72$ \\
Adults & 425 & $64 \cdot 0$ & 168 & $82 \cdot 7$ & $7 \cdot 90$ \\
Total & 664 & & 203 & & $30 \cdot 86$
\end{tabular}

\section{RESULTS}

Between December 1981 and March 1983, 258 cat sightings were made on Marion Island (Fig 1); 134 of these represented 104 different individuals within the defined study area. The 1982 population was estimated at 615 (S.E. $=107)$ cats (Table 1), a decrease of $29 \%$ year $^{-1}(\bar{r}=-0 \cdot 343)$ since the introduction of FPL in 1977 when the population numbered 3405 cats (van Aarde 1978). Population estimates for 1981-82 and 1982-83 for a comparable part of the study area were $577($ S.E. $=122)$ and $531($ S.E. $=115)$ respectively, a decrease of $8 \%$ year $^{-1}(\vec{r}=-0.083)$, which was not significant $(t=1.47)$.

The population's age structure changed significantly $\left(\chi_{2}^{2}=30.86 ; P<0.005\right)$ from 1975 to 1982 (Table 2), with subadult numbers decreasing $\left(\chi_{1}^{2}=22 \cdot 72 ; P<0.005\right)$ and adult numbers increasing $\left(\chi_{1}^{2}=7.90 ; P<0.005\right)$.

The age distribution of the 1981-82 and 1982-83 samples did not differ $\left(\chi_{7}^{2}=13 \cdot 39\right)$ and it was assumed that the population's age distribution was stable. These age frequencies were, therefore, grouped together (observed), corrected and smoothed (Table 3). Sex specific age distribution for the observed and corrected frequencies did not differ significantly $\left(\chi_{7}^{2}=10.26\right.$ and 4.64 for males and females, respectively). Similarly, there were no differences between the age distributions of the sexes of the corrected frequencies $\left(\chi_{7}^{2}=10.99\right)$. The smoothed and corrected frequencies also did not differ significantly $\left(\chi_{7}^{2}=3 \cdot 49\right)$. The age distributions of the 1975 and 1982 populations did not differ significantly $\left(\chi_{7}^{2}=10.87\right)$ from each other (Fig. 2). However, the ratio of subadults (age class I) to adults (age classes II-IX) differed significantly $\left(\chi_{1}^{2}=5 \cdot 02 ; P<0.05\right.$, Fig. 2).

Litter size at birth was unknown but mean prenatal litter size was $4 \cdot 50$ (S.E. $=1 \cdot 7 ; n=8$ ) and did not differ from the 1975 (control) value of 4.59 (S.E. $=1 \cdot 12$ ). The mean 4.56 $($ S.E. $=1 \cdot 29)$ of the two subsamples was, therefore, used in all computations. Litter size at 
TABLE 3. Age distribution of the 1982 population on Marion Island

\begin{tabular}{lrrrrrr} 
& \multicolumn{2}{c}{ Observed } & \multicolumn{2}{c}{ Corrected } & \\
Age class & Males & Females & Males & Females & Total & Smoothed \\
I (4-12 months) & 11 & 11 & 22 & 11 & 33 & $27 \cdot 3$ \\
II (1 year) & 21 & 11 & 11 & 4 & 15 & $20 \cdot 5$ \\
III (2 years) & 7 & 5 & 7 & 7 & 14 & $16 \cdot 7$ \\
IV (3 years) & 9 & 8 & 10 & 10 & 20 & $14 \cdot 2$ \\
V (4 years) & 8 & 12 & 6 & 10 & 16 & $12 \cdot 2$ \\
VI (5 years) & 7 & 11 & 2 & 6 & 8 & $10 \cdot 0$ \\
VII (6 years) & 1 & 5 & 2 & 4 & 6 & $7 \cdot 6$ \\
VIII (7 years) & 2 & 1 & 2 & 4 & 6 & $5 \cdot 1$ \\
IX (8 years) & 1 & 3 & & & & $2 \cdot 9 *$
\end{tabular}

* Based on extrapolation from the log-polynominal function, $N_{\mathrm{x}}=1 \cdot 439$ $0 \cdot 151 x^{1}+0 \cdot 028 x^{2}-0 \cdot 003 x^{3}(r=0 \cdot 900)$, used to smooth age distribution.

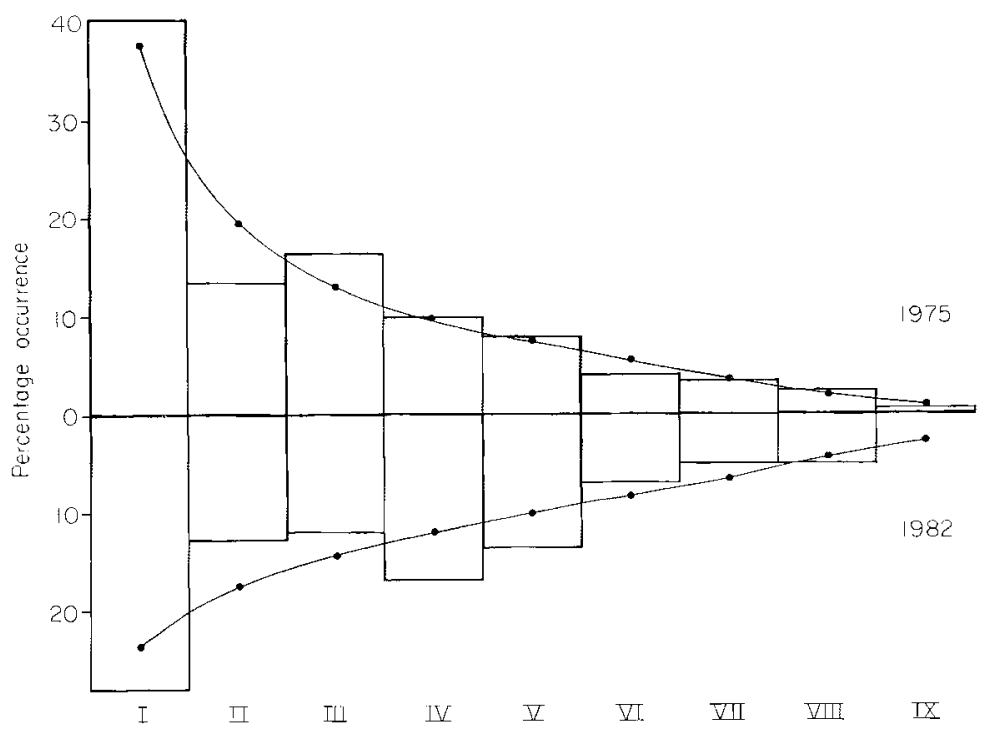

Fig. 2. Age structure of the 1975 (control) and 1982 cat populations of Marion Island.

weaning decreased from $2.66($ S.E. $=0.76)$ in 1975 to $1.65($ S.E. $=0.71)$ in $1982\left(t_{70}=5 \cdot 80\right.$; $P<0.005)$. The birth season lasted from mid-September to mid-March (mean date of birth $=30$ December $($ S.E. $=80$ days) $)$ with adult females producing two litters per season.

The age specific fecundity $\left(F_{x}\right)$ schedules based on litter size and the frequency of pregnant and lactating females in each age class during the breeding season are provided in Table 4 . This indicates that $93.6 \%$ of all females collected during the breeding season were reproductively active, and mean age specific fecundity $\left(F_{x}\right)$ was estimated as 1.54 surviving female births per female per season for all reproductive age classes. Age specific fecundity was lower during 1975 for age classes II, VIII and IX and higher for age classes 
TABLE 4. Observed age-specific reproductively active females during the breeding season of the cat population on Marion Island

$\begin{array}{lcc}\text { Age class } & \text { Percentage } & n \\ \text { I } & 0 & \\ \text { II } & 100 \cdot 0 & 5 \\ \text { III } & 100 \cdot 0 & 5 \\ \text { IV } & 100 \cdot 0 & 4 \\ \text { V } & 80 \cdot 0 & 5 \\ \text { VI } & 85 \cdot 7 & 7 \\ \text { VII } & 100 \cdot 0 & 4 \\ \text { VIII } & - & 0 \\ \text { IX } & 100 \cdot 0 & 1 \\ \text { Total } & & 31\end{array}$
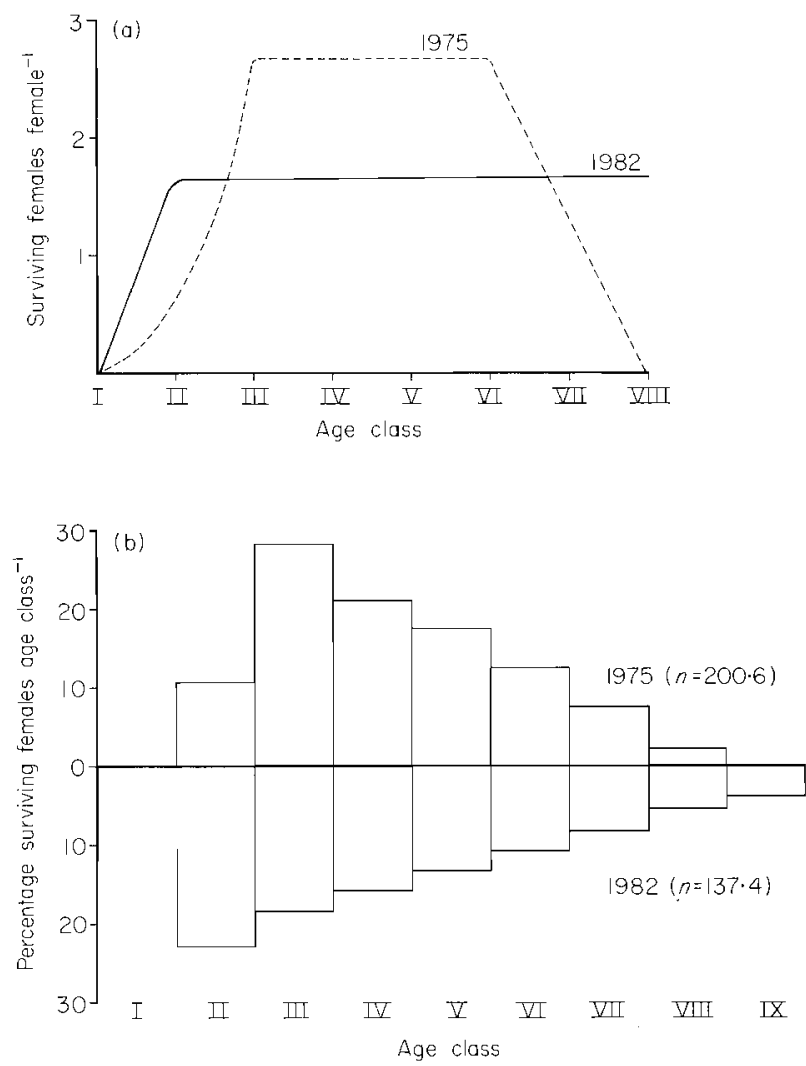

FIG. 3. Age-specific fecundity of the control and 1982 cat populations of Marion Island.

III-VII than in 1982 (Fig. 3a). Age class II had the highest reproductive output of all age classes in 1982, whereas in 1975, age class III was the highest (Fig. 3b).

Intrinsic rate of increase $(r)$ for 1982 was 1.608 , and probabilities of surviving $\left(l_{x}\right)$, or dying $\left(d_{x}\right)$, and survival $\left(p_{x}\right)$ and mortality rates $\left(q_{x}\right)$ based on $\bar{r}=-0.083$ and an assumed stable age distribution are presented in Table 5 . 
TABLE 5. Life table statistics for the 1982 cat population on Marion Island $(\vec{r}=0.083)\left(x\right.$ is the age class, $f_{x}$ is the smoothed age frequency, $l_{x}$ is the probability of surviving, $d_{\mathrm{x}}$ is the probability of dying, $p_{\mathrm{x}}$ is the survival rate and $q_{\mathrm{x}}$ is the mortality rate)

\begin{tabular}{lccccc}
$x$ & $f_{\mathrm{x}}$ & $l_{\mathrm{x}}$ & $d_{\mathrm{x}}$ & $p_{\mathrm{x}}$ & $q_{\mathrm{x}}$ \\
I & $137.4 *$ & 1.0000 & 0.8627 & 0.1373 & 0.8627 \\
II & 20.5 & 0.1373 & 0.0343 & 0.7502 & 0.2498 \\
III & 16.7 & 0.1030 & 0.0224 & 0.7825 & 0.2175 \\
IV & 14.2 & 0.0806 & 0.0169 & 0.7903 & 0.2097 \\
V & 12.2 & 0.0637 & 0.0156 & 0.7551 & 0.2449 \\
VI & 10.0 & 0.0481 & 0.0145 & 0.6985 & 0.3015 \\
VII & 7.6 & 0.0336 & 0.0128 & 0.6190 & 0.3810 \\
VIII & 5.1 & 0.0208 & 0.0099 & 0.5240 & 0.4760 \\
IX & 2.9 & 0.0109 & - & 0.0000 & 1.0000 \\
\multicolumn{7}{l}{ * Estimated from fecundity rates. }
\end{tabular}

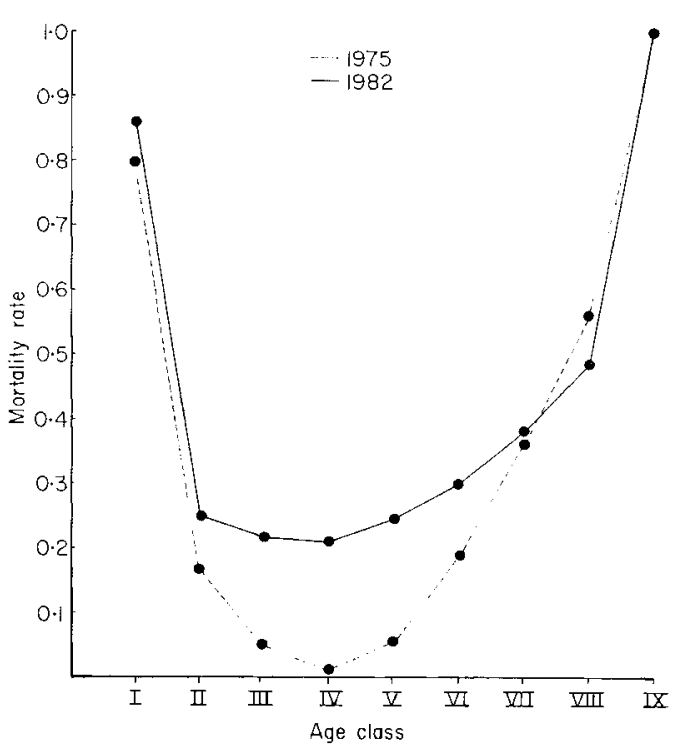

FIG. 4. Mortality rates of the cat populations on Marion Island in 1975 and 1982.

Mortality rates decreased after the first year, remaining relatively constant until age class $\mathrm{V}$ when they started to increase to attain a value of 1.0 in age class IX (Fig. 4).

The ratio of susceptible to immune cats (for FPL) did not change from 1978 to 1982 $\left(\chi_{1}^{2}=0.53\right)$. However, antibody titres did change significantly $\left(\chi_{6}^{2}=28.59 ; P<0 \cdot 005\right)$, with a decrease in the frequency of the high antibody titres $(1: 512)$ to lower titres $(1: 32)$ from 1978 to 1982 (Table 6). During 1982 most (65\%) adult females had titre values of $1: 128$ to $1: 1024$, with c. $21 \%$ having titres from $1: 16$ to $1: 64$, and $14 \%$ being susceptible (Table 7 ). FVR antibody titres changed significantly from 1976 (before the introduction of FPL) to $1978\left(\chi_{2}^{2}=8.09 ; P<0.025\right)$. This was due to an increase in the frequency of higher antibody titres, although it decreased again from 1978 to 1982 (Table 6). However, this 
TABLE 6. The frequency of FPL and FVR antibody titres of the cat population on Marion Island

\begin{tabular}{|c|c|c|c|c|c|c|c|c|c|c|c|c|c|c|}
\hline \multirow{2}{*}{\multicolumn{2}{|c|}{ Year }} & \multicolumn{13}{|c|}{ FPL antibody titres } \\
\hline & & 0 & 16 & 32 & 64 & 128 & 256 & & 512 & 1024 & 20 & & 4096 & \\
\hline & 1978 & 12 & 0 & 1 & 7 & 9 & 9 & & 10 & 5 & 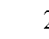 & & 2 & \\
\hline & 1982 & 19 & 5 & 22 & 23 & 17 & 13 & & 15 & 1 & c & & 0 & \\
\hline \multirow[t]{2}{*}{ Year } & \multicolumn{14}{|c|}{ FVR antibody titres } \\
\hline & 0 & 2 & 5 & 10 & 15 & 20 & 25 & 30 & 40 & 60 & 75 & 80 & 125 & 375 \\
\hline $1976^{*}$ & 14 & 1 & - & 2 & - & 4 & - & 1 & 3 & 1 & - & 3 & - & - \\
\hline 1978 & 22 & - & 1 & - & 6 & - & 8 & - & - & - & 10 & - & 6 & 8 \\
\hline 1982 & 35 & - & 11 & - & $\ldots-$ & - & 29 & - & - & - & - & - & 13 & - \\
\hline
\end{tabular}

* Before the introduction of FPL.

TABLe 7. Percentage of FPL antibody titres of the adult female cats on Marion Island in $1982(n=43)$

$\begin{array}{lcccccccc}\text { Titres } & 0 & 16 & 32 & 64 & 128 & 256 & 512 & 1024 \\ \text { Percentage } & 14 \cdot 0 & 2 \cdot 3 & 7 \cdot 0 & 11 \cdot 6 & 18 \cdot 6 & 25 \cdot 6 & 18 \cdot 6 & 2 \cdot 3\end{array}$

TABLE 8. The frequency of phenotypes of the 1975 and 1982 cat populations on Marion Island

\begin{tabular}{lcccccccc} 
& Non-agouti & Agouti & \multicolumn{2}{c}{ Tabby } & \multicolumn{2}{c}{ Dilution } & \multicolumn{2}{c}{ Piebald } \\
Year & $\mathrm{a}$ & $\mathrm{a}^{+}$ & $\mathrm{t}^{\mathrm{b}}$ & $\mathbf{1}^{+}$ & $\mathrm{d}$ & $\mathrm{d}^{+}$ & $\mathrm{S}$ & $\mathrm{s}^{+}$ \\
$1975^{*}$ & 530 & 113 & 37 & 76 & 11 & 645 & 192 & 464 \\
1982 & 217 & 41 & 16 & 31 & 1 & 257 & 70 & 188 \\
$\chi^{2}$ & 0.37 & & 0.03 & & 2.38 & & 0.41 &
\end{tabular}

* van Aarde \& Robinson (1980).

decrease was not significant $\left(\chi_{2}^{2}=5 \cdot 96\right)$. There was also no significant change in the immune and susceptible cats between 1976 and $1978\left(\chi_{1}^{2}=1 \cdot 22\right)$ and between 1978 and $1982\left(\chi_{1}^{2}=0 \cdot 39\right)$; FPL and FVR were independent of each other in the proportion of immune and susceptible cats in $1982\left(\chi_{1}^{2}=2 \cdot 00\right)$. The frequency of occurrence of the different phenotypes also did not change significantly from 1975 to 1982 (Table 8).

\section{DISCUSSION}

Control of pest species can be achieved only when the rate of control is higher than the population's rate of increase. Conditions prevailing on the sub-Antarctic Marion Island rendered mechanical control methods (i.e. hunting and trapping) ineffective as control measures in the short term with such a large population of cats (van Aarde \& Skinner 1981). The successful deliberate introduction of a virulent strain of feline parvo virus to the island in an attempt to create an epidemic disease (Howell 1984) provided an 
opportunity to evaluate the effect of such a biological control measure on the demography of a susceptible and isolated feline population.

Earlier analyses on the effect of FPL on the population include the reported reduction in density indices based on information obtained from line transect surveys (van Aarde 1984), and a decrease in postweaning litter size (Howell 1984). The most conspicuous change that has taken place in the population was a drastic decrease in density as estimated from intensive surveys of selected stratified grids sampled before and after the introduction of FPL. Criteria for the reliability of the method and applicability to the Marion Island situation have been discussed by van Aarde (1979). The distribution pattern of cats around the island was not affected by the viral disease, confirming earlier speculation that the clumped distribution of cats is not a factor of density, but rather of food availability (van Aarde 1980).

Observed changes in the relative (Table 2) and year class (Table 3 ) age structures of the population resulted from a decrease in subadult numbers. The hypothesis that these changes are due to FPL infection is supported by the fact that morbidity and mortality sccur mainly amongst cats < 1 year old (Fastier 1968; Reif 1976).

Kittens from cats with low $(1: 10$ to $1: 100)$ and moderate titres $(1: 100$ to $1: 1000)$ possess maternally derived antibodies for 4-8 and 8-12 weeks, respectively (Scott, Csiza \& Gillespie 1970). Since the majority of the 1982 adult females possessed moderate titres (Table 7), it is expected that most of the juveniles that died of FPL were older than three months, resulting in a decrease in subadult numbers. The decrease in postweaning litter size from 1975 to 1982 could, therefore, be the result of kittens losing their maternally derived resistance between $4-8$ weeks of age as a result of females having low titres.

Reif (1976) found FPL peaking in occurrence from July to September in Pennsylvania, U.S.A., and concluded that this seasonality and seasonal breeding of cats must be incorporated when constructing an epidemiological model to illustrate the phenomenon of herd immunity. Fox et al. (1971) illustrated that the number of susceptibles and the probability of contact between them determine epidemic potentials in random mixing populations, and that population size does not influence the probability of spread. (Contact rate is the probability that any two animals in a population will make contact which will result in the transmission of an agent from an infectious to a susceptible individual (Fox et al. 1971) or, simply stated by Reif (1976), when the number of susceptibles increases and contact rates remain constant, the number of new cases will increase). This happens 2-3 months after birth when kittens become susceptible, which esults in an epidemic of FPL, mainly amongst kittens (Reif 1976). Because of the high juvenile mortality rate and seasonal breeding (van Aarde 1978), a seasonal epidemic of FPL has probably occurred annually on Marion Island since the introduction of the virus.

Since the age distributions of the 1975 and 1982 populations did not differ, the patterns of mortality were similar, but the higher mortality rates in 1982 are due to the lower frequency of cats in age class I. The greater proportion of adults and a higher fecundity of age class II in 1982 resulted in a higher intrinsic rate of population increase than in 1975 $\left(r_{1975}=1 \cdot 117 ; r_{1982}=1 \cdot 608\right)$. The higher fecundity in age classes II, VIII and IX is probably a reaction of thie population to the lowered density. Longevity of the Marion Island cats has been estimated at 8 years and it is therefore possible that the lowered fecundity of age classes VIII and IX in 1975 was not age specific but rather due to smaller samples taken in these age classes (e.g. van Aarde (1983) did not collect any females in age class IX). On the other hand, since cats (even females with kittens) changed shelters regularly on Marion Island, breeding shelters could be a limiting factor for age class II females at high densities (e.g. before the introduction of FPL), because of the overlapping home ranges of females. 
Fresh carcasses of cats could not be collected and none of the cats shot, caught or sighted, showed clinical symptoms of FPL. The clinical features of FPL (Carpenter 1971) are of such a nature that cats would die in their subterranean shelters. Corpses lying in the open on Marion Island are, furthermore, rapidly scavenged by skuas Catharacta antarctica (Mathews), gulls Larus dominicanus (Lichtenstein), sheathbills Chionis minor (Hartlaub) or giant petrels Macronectes spp. Therefore, mortality could not be ascribed directly to FPL. However, the shift from moderate to low titres of FPL illustrates that FPL did affect the cat population but that it no longer spreads as efficiently. Serum samples collected from cats taken from around the island also illustrated that FPL has spread successfully throughout the population. Since FPL and FVR were independent of each other, the increase of antibody titres of FVR after the introduction of FPL could not be ascribed to FPL. As FVR is an endemic disease of the Marion Island cats (Howell 1984), the increase in FVR titres may have been part of a natural fluctuating cycle of the disease. FPL was, therefore, directly responsible for the decrease in cat numbers, but had no selective effect on the cat population's phenotypic profile.

The decrease of $29 \%$ year $^{-1}$ over 5 years (1977-82) as compared to $8 \%$ year $^{-1}$ over the fieldwork period (1981-82 to 1982-83) suggests that the population may be stabilizing. The shift in antibody titres of FPL supports this conclusion.

Lowered fecundity, a drastic decrease in density, a change in the age structure and a decrease in growth rate illustrated by our analyses indicate that FPL can be used effectively as a biological control measure to reduce the density of susceptible cat populations as part of an effort either to control or to eliminate such populations.

\section{ACKNOWLEDGMENTS}

Logistical and financial support was provided by the South African Department of Transport on advice of the South African Scientific Committee for Antarctic Research. Serum samples were analysed by the Department of Infectious Diseases, University of Pretoria, Onderstepoort, under supervision of Professor P. G. Howell. We wish to acknowledge Drs M. N. Bester and G. A. Robinson for their support. Mrs A. Nel drew the figures.

\section{REFERENCES}

Carpenter, J. L. (1971). Feline panleukopaenia: Clinical signs and differential diagnosis. Journal Americar. Veterinary and Medical Association, 6, 857-862.

Caughley, G. (1977). Analysis of Vertebrate Populations. Wiley and Sons, New York.

Fastier, L. B. (1968). Feline panleucopaenia. A serological study. Veterinary Record, 83, 653-655.

Fox, J. P., Elveback, L., Scott, W., Gatewood, L. \& Ackerman, E. (1971). Herd immunity: basic concept and relevance to public health immunization practices. American Journal of Epidemiology, 94, 179-189.

Gillespie, J. H. \& Scott, F. W. (1973). Feline viral infections. Advances in Veterinary Science and Comparative Medicine, 17, 163-200.

Howell, P. G. (1984). An evaluation of the biological control of feral cat Felis catus (Linnaeus, 1758). Acta Zoologica Fennica, 172, 111--113.

Huntley, B. J. (1967). A preliminary account of the vegetation of Marion and Prince Edward Island. South African Journal of Science, 63, 235241

Johnson, R. H. (1971). Serologic proceedings for the study of feline panleukopenia. Journal American Veterinary Medical Association, 158, 876-884.

Jolly, G. M. (1969). Sampling methods for aerial censuses of wildlife populations. East African Agricultural and Forestry Journal, Special Issue, 46--55.

Michod, R. E. \& Anderson W. A. (1980). On calculating demographic parameters from age frequency data. Ecology, 61, 265-269. 
Reif, J. S. (1976). Seasonality, natality and herd immunity in feline panleucopaenia. American Journal of Epidemiology, 103, 81-87.

Schulze, B. R. (1971). The climate of Marion Island. Marion and Prince Edward Islands; report on the South African Biological and Geological Expedition 1965/66 (Ed. by E. M. van Zinderen Bakker, J. M Winterbottom \& R. A. Dyer), pp. 16 31. A. A. Balkema, Cape Town.

Scott, F. W., Csiza, C. R. \& Gillespie, J. H. (1970). Maternaily derived immunity to feline panleucopaenia. Journal American Veterinary Medical Association, 156, 439-453.

van Aarde, R. J. (1978). Reproduction and population ecology in the feral house cat Felis catus on Marion Island. Carnivore Genetics Newsletter, 3, 288-316.

van Aarde, R. J. (1979). Distribution and density of the feral house cat Felis catus on Marion Island. South African Journal of Antarctic Research, 9, 1419

van Aarde, R. J. (1980). The diet and feeding behaviour of feral cats, Felis catus at Marion Isiand. South African Journal of Wildlife Research, 10, 123-128.

van Aarde, R. J. (1983). Demographic parameters of the feral cat Felis catus population at Marion Island. South African Journal of Wildlife Research, 13, 12-16.

van Aarde, R. J. (1984). Population biology and the control of feral cats on Marion Island. Acta Zoologica Fennica, 172, 107-110.

van Aarde, R. J. \& Robinson, T. J. (1980). Gene frequencies in feral cats Felis catus on Marion Island. Journal of Heredity, 71, 366368 .

van Aarde, R. J. \& Skinner, J. D. (1981). The feral cat population at Marion Island: characteristics, colonization and control. Comité National Français Recherches Antarctiques, 51, 281-288.

Verwoerd, W. J. (1971). Geology. Marion and Prince Edward Islands; report on the South African Biological and Geological Expedition, I965/1966 (Ed. by E. M. van Zinderen Bakker, J. M. Winterbottom and R. A. Dyer), pp. $40-62$. A. A. Balkema, Cape Town.

(Received 28 October 1985; revision received 10 June 1986) 